\title{
Solitary Plasmacytoma of Clavicle - A Rare Case Presentation
}

\author{
Mohammad Shahid ${ }^{1 *}$, Nayeem Zafar Hali², Aysha Mubeen¹, Sufian Zaheer ${ }^{1}$ and Julfiqar ${ }^{2}$
}

${ }^{1}$ Department of Pathology, Jawaharlal Nehru Medical College, AMU, Aligarh 202002, UP, India

${ }^{2}$ Department of Orthopaedics, Jawaharlal Nehru medical College, AMU, Aligarh 202002, UP, India

\begin{abstract}
Plasmacytoma is a localized collection of malignant plasma cells. The disease is divided into Solitary plasmacytoma of the bone (SPB) and extramedullary plasmacytoma (EMP) which are both distinct entity. SPB usually occur in the bones characteristically affected in multiple myeloma and EMP was most frequently located in the oronasopharynx and paranasal sinuses, with a $15-30 \%$ incidence of regional lymph node involvement. We report a case of Solitary plasmacytoma of medial end clavicle resulting in pain and swelling of left clavicle in a 28 year old farmer. SPB can involve any bone in the body but involvement of medial end of clavicle though reported is a very rare presentation.
\end{abstract}

Keywords: Solitary plasmacytoma bone; Multiple myeloma; Clavicle; Electrophoresis

\section{Introduction}

'Plasmacytoma' is one of the plasma cell neoplasms locally infiltrating bones or spreading to extramedullary sites from the bones [1]. The new World Health Organization (WHO) criteria define solitary plasmacytoma of bone (SPB) as 'a localized bone tumor consisting of plasma cells identical to those seen in plasma cell myeloma, which appears as a solitary lytic lesion on radiological examination [1].

Considerable debate exists regarding the relationship of SPB and EMP to multiple myeloma (MM). Most authors agree that EMP has a different natural history from both SPB and MM and believe that SPB is simply an early presentation of MM whereas others consider that SPB is a clinical entity distinct from MM [2]. Multiple myeloma is the most common primary malignancy of bone, representing $43 \%$ of primary malignancies of bone in the Mayo Clinic series [3]. Bone pain is the most common complaint for patients with SPB as with multiple myeloma $[4,5]$.

Primary bone tumours and tumour-like lesions of clavicle are uncommon. Klein et al. [6] found that only $0.45 \%$ of more than 1300 primary bone tumours involved the clavicle. Smith et al. [7] in a review of 35 primary bone tumours of the clavicle that have been treated at the Memorial Sloan-Ketterin Cancer centre reported only five benign lesions. Primary bone tumours of the Clavicle are more likely to be malignant than benign. Systemic problems such as weakness, weight loss, anaemia, thrombocytopenia, peripheral neuropathy (especially with the osteosclerotic type of multiple myeloma), hypercalcemia, or renal failure frequently are present at the time of diagnosis in multiple myeloma but in contrast these systemic findings are absent in SPB [8]. Symptoms of systemic myeloma usually are of short duration because of the aggressive nature of the disease. Pathological fractures are relatively common. The spine is the most common location of multiple myeloma followed by the ribs and pelvis. Roentgenographically, multiple myeloma appears as multiple, "punched out," sharply demarcated, purely lytic lesions without any surrounding reactive sclerosis. Lack of reactive bone formation also is demonstrated by the fact that most lesions are negative on bone scan. Occasionally, myeloma is characterized by marked bone expansion, giving rise to a "ballooned" appearance. The diagnosis usually can be confirmed by serum immunoelectrophoresis, which demonstrates a monoclonal gammopathy. In contrast to multiple myeloma diagnostic criteria for plasmacytoma is solitary lytic bone lesion or extraosseous/ extramedullary mass of neoplastic plasma cells with no evidence of plasmacytosis in other bone marrow sites, absence of clinical features of plasma cell myeloma (renal insufficiency/ anemia/ hypercalcemia) and negative bone scan.

\section{Case Report}

A 28-year-old male farmer, presented with a 3-month history of swelling and pain around left shoulder. Patient accidentally noticed a small swelling of about peanut size on the inner aspect of left clavicle, which was gradually progressive. After few days the patient started to feel localized pain around inner aspect of left clavicle. The pain increased on physical activity. Clinical examination revealed tenderness at the medial end of swelling in the supraclavicular region on medial side. Swelling was of size about $3 \times 2 \mathrm{~cm}$ in size and was firm to hard in consistency. Range of movement at left shoulder was painfully reduced. Radiographs of left clavicle showed a lytic expansile lesion involving medial $1 / 3^{\text {rd }}$ of left clavicle associated with a soft tissue mass in the apical region of chest (Figure 1). Spiral CT of upper thorax shows an expansile lytic lesion in the medial end of left clavicle causing endosteal scalloping with multiple nodular calcifications visualized in soft tissue. No periosteal reaction and

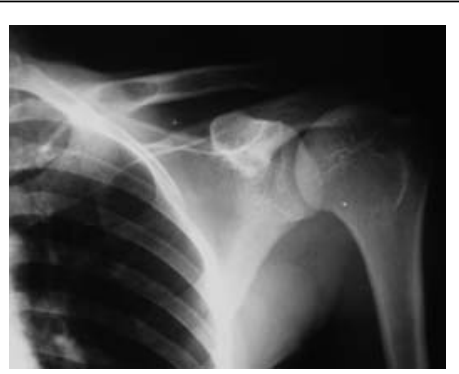

Figure 1: Radiographs of left clavicle showed a lytic expansile lesion involving medial end of left clavicle associated with a soft tissue mass in the apical region of chest.

*Corresponding author: Dr. Mohammad Shahid, Senior Resident, Department of Pathology, Jawaharlal Nehru Medical College, AMU, Aligarh, UP, INDIA, Tel: +918126974063; Fax: 91-5712700136; E-mail: shahidaftab@gmail.com

Accepted October 18, 2010; Accepted October 18, 2010; Published Octobe 18,2010

Citation: Shahid M, Hali NZ, Mubeen A, Zaheer S, Julfiqar (2010) Solitary Plasmacytoma of Clavicle - A Rare Case Presentation. J Cytol Histol 1:103. doi:10.4172/2157-7099.1000103

Copyright: ( $) 2010$ Shahid M, et al. This is an open-access article distributed under the terms of the Creative Commons Attribution License, which permits unrestricted use, distribution, and reproduction in any medium, provided the original author and source are credited. 
breach of the bony cortex was seen. CT scan was highly suggestive of chondrosarcoma (Figure 2). FNAC from the lesion showed small round cell tumour but no definitive diagnosis could be made. Patient underwent a wide surgical excision of the tumour through anterior approach (Figure 3). Per-operatively lesion was not compressing the neurovascular structures in the root of the neck. Excised mass was sent for histopathological examination.

Gross histopathological examination showed irregular light brown congested tissue piece $6 \times 3 \times 1.5 \mathrm{~cm}$. Cut surface was pale, white to dark brown with attached soft tissue and bone pieces. Microscopic examination showed tumour composed of sheets of medium size to large plasmacytoid cells with enlarged nucleus having cart wheel chromatin pattern, many binucleated and multinucleated cell highly suggestive of plasma cell neoplasm (Figure 4).

Thereafter, Plain radiographs of spine, chest, pelvis, skull and long bones were done without any concomitant pathological lesion. Bone scan showed isolated abnormal uptake at the medial end of left clavicle. Complete blood cell count, serum electro-phoresis, urinary protein electrophoresis (24-h urine sample), alkaline

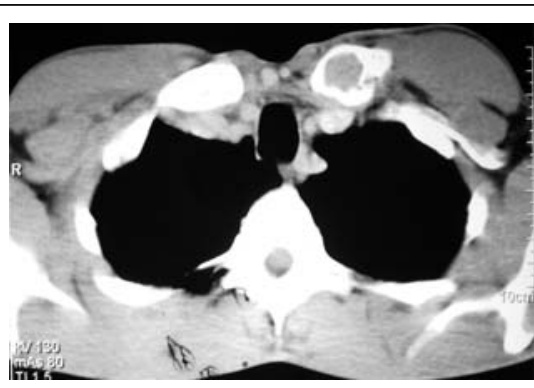

Figure 2: Spiral CT of upper thorax shows an expansile lytic lesion in the medial end of left clavicle causing endosteal scalloping with multiple nodular calcifications visualized in soft tissue.

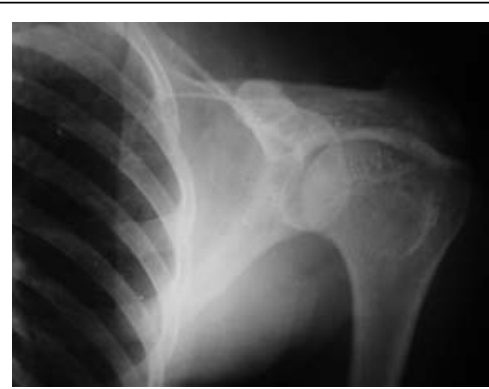

Figure 3: Shows post operative x-ray of patient,after excision of clavicle.

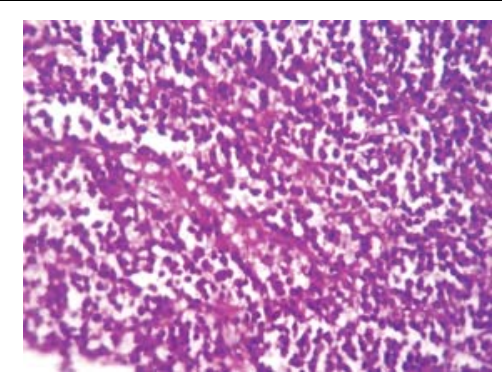

Figure 4: Microscopic examination showed tumour composed of sheets of medium size to large plasmacytoid cells with enlarged nuclei, focal nuclei with few binucleate cells highly suggestive of plasmacytoma. phosphatase, lactic dehydrogenase, C-reacting protein, ECR and serum $\mathrm{Ca}^{2+}$ and $\mathrm{PO}_{4}^{3-}$ showed normal values. On the advice of the Oncologists, chemotherapy was started in form of oral thalidomide [9]. Three month postoperatively patient was doing well with almost full range of movement at left shoulder joint. He was doing all his routine activities without any new complaint. Patient is undergoing chemotherapy at present.

\section{Discussion}

Plasma cell neoplasms account for approximately $1-2 \%$ of human malignancies and occur at a rate of about $3.5 / 100,000$ per year $[10,11]$. Less than $10 \%$ of patients present a solitary plasmacytoma in either bone marrow (SBP) or a soft tissue site (EMP). SBP affects fewer than $5 \%$ of patients with plasma cell myeloma. The diagnosis is based on histological evidence of a single lesion consisting of monoclonal plasma cells identical to those seen in multiple myeloma, a negative skeletal survey and no evidence of tumor in the bone marrow. Transformation to overt multiple myeloma occurs in almost $50 \%$ of patients with solitary plasmacytoma of bone. However, progression may occur as long as 15 years later [12]. Roentgen graphically, plasmacytoma appears as multiple, "punched out," sharply demarcated, purely lytic lesions without any surrounding reactive sclerosis. The diagnosis usually can be confirmed by Biopsy. Histologically, plasmacytoma appears as sheets of plasma cells. These are small, round blue cells with "clock face" nuclei and abundant cytoplasm with a perinuclear clearing or "halo". Plasmacytoma will exhibit monoclonal kappa or lambda light chains, whereas the plasma cells of reactive condition chronic osteomyelitis will be polyclonal. Also, myeloma cells usually stain positive for the natural killer antigen CD56, whereas reactive plasma cells usually do not. Immunohistochemistry also can be helpful in poorly differentiated cases when lymphoma could be in the differential diagnosis. Plasmacytoma of medial end of clavicle is rare and Shih et al. [13] found only one case solitary plasmacytoma of lateral clavicle out of 32 cases of Solitary plasmacytoma. Panagopoulos A et al. [14] found one clase of solitary bone plasmaytoma of lateral clavicle which was radiotherapy resistant. Smith et al. [15] in their study at Memorial Sloan- Kettering cancer centre over a span of 50 years on lesion of clavicle only six cases of solitary plasmacytoma of clavicle was found, with only one arising from medial end. Carter and Rushman [16] reported one case of solitary plasmacytoma of lateral end of clavicle. Excision of solitary plasmacytoma is recommended when possible. Radiotherapy has been shown to be successful for local control of plasmacytoma. However chemotherapy has been recommended to patients with disseminated disease and evidence of disease progression. Long term follow up is necessary because of $35 \%$ to $55 \%$ of patient; multiple myeloma develops often 10 to 12 years after initial diagnosis.

\section{Reference}

1. Jaffe ES, Harris NL, Stein H, Vardiman JW (2001) World Health Organization Classification of Tumours: Pathology and Genetics, Tumours of Haematopoietic and Lymphoid Tissues. Ann Oncol 13: 490-491.

2. Shih LY, Dunn P, Leung WM, Chen WJ, Wang PN (1995) Localised plasmacytomas in Taiwan: comparison between extrameduliaryplasmacytoma and solitary plasmacytoma of bone. $\mathrm{Br} \mathrm{J}$ Cancer 71: 128-133.

3. Dahlin DC (1967) Plasma cell Myeloma: In bone tumour. Springfied III Charles C Thomas 116.

4. Lauchlam JM (1973) Scotland Journal of bone and joint surgery. British 55

5. Griffiths DL (1996). Orthopaedics Aspect of Myelomatosis. J Bone Joint Surg Br 48: 703-728.

6. Kleins, Kuppers R (1999) The New England Journal of Medicine. 341: 1520. 
Citation: Shahid M, Hali NZ, Mubeen A, Zaheer S, Julfiqar (2010) Solitary Plasmacytoma of Clavicle - A Rare Case Presentation. J Cytol Histol 1:103. doi:10.4172/2157-7099.1000103

Page 3 of 3

7. Smith J, Yuppa F, Watson RC (1988) Primary tumor and tumor-like lesion of clavicle. Skeletal Radiol 17: 235-246.

8. Resnik D, Greenway GD, Bardwick PA, Zvaifler NJ, Gill GN, et al. (1981) Plasma cell Dyscrasia with Polyneuropathy, Organomegaly, Endocrinopathy, M-Protein and Slin changes. The POEMS Syndrome. Distinctive radiographic abnormalities. Radiology 140: 17-22.

9. Singhal S, Mehta J, Desikan R, Ayers D, Roberson P, et al. (1999) Antitumor activity of Thalidomide in Refractory Multiple myeloma. N Engl J Med 341: 1565-1571.

10. Bolek TW, Marcus RB, Mendenhall NP (1996) Solitary plasmacytoma ofbone and soft tissue. Int J Radiat Oncol Biol Phys 36: 329-333.

11. Tsang RW, Gospodarowicz MK, Pintilie M, Bezjak A, Wells W, et al. (2001)
Solitary plasmacytoma treated with radiotherapy: impact of tumor size on outcome. Int J Radiat Oncol Biol Phys 50: 113-120.

12. Dimopoulos MA, Moulopoulos LA, Maniatis A, Alexanian R (2000) Solitary plasmacytoma of bone and asymptomatic multiple myeloma. Blood 96: 20372044

13. Shih LY, Dunn P, Leung WM, Chen WJ, Wang PN (1995) Localised plasmacytomas in Taiwan: comparison between extrameduliary plasmacytoma and solitary plasmacytoma of bone. Br J Cancer 71: 128-133.

14. Panagopoulas A, Megas P, Kaisidis A, Dimakopoulos P (2006) Radiotherapy resistant Solitary Bone Plasmacytoma of Clavicle. European Journal of Trauma 32: 190-193.

15. Carter PM, Rushman RW (1974) Solitary Plasmacytoma of Clavicle. Proc R Soc Med 67: 1097-1098. 